\title{
LANGUAGE SOCIALIZATION OF AFFECT IN MANDARIN PARENT-CHILD CONVERSATION
}

\author{
Chiung-chih Huang
}

\begin{abstract}
This study aimed to investigate language socialization of affect in Mandarin parent-child interaction. Natural conversations between Mandarin-speaking two-year-olds and their parents were analyzed, focusing on the lexicon of affect words and the conversational interactions in which these words were used. The results showed that the children tended to use the type of affect words which encoded specific affective states, with the children as the primary experiencers. The parents, on the other hand, tended to use affect words not only to encode affective states but also to express evaluative characterizations. They often used affect words to negotiate with the children the appropriate affective responses to a variety of stimuli or to socialize the children's behaviors into culturally approved patterns. In addition, it was found that the structure of conversational sequences served as a discourse-level resource for the socialization of affect. The findings were further discussed in relation to Clancy's (1999) model of language socialization of affect.
\end{abstract}

Keywords: Language socialization; Affect; Mandarin; Parent-child conversation.

\section{Introduction}

Research on human emotions has received much attention in the disciplines of psychology, anthropology and linguistics. In the area of child language acquisition, the development of 'emotion talk' also deserves attention. In order to become communicatively competent, it is important for language-learning children to learn how to express and talk about feelings in appropriate ways, and to recognize others' moods and emotions.

Previous studies have raised the controversial question of the role of nature vs. nurture in the development of human emotions. Hochschild (1979) contrasts two models of emotional development: the biological model and the socialization model. In the first model, emotion is related to biologically given instincts or impulses. In this view, emotions are regarded as organismic functions and are fixed or universal phenomena. In the second model, emotions are viewed as subject to the influence of socialization. As suggested by Hochschild (1979: 563), "we do feel, we try to feel, and we want to try to feel".

Previous studies of emotions, however, have focused mostly on the measurement and development of emotional behavior, such as infants' facial expressions and the relationship of emotional expressions to particular situations (e.g., Izard 1977; Malatesta \& Haviland 1982; Ortony et al. 1988; Scherer 1982). The perspectives these studies adopted were derived mainly from the biological model. The ways in which emotions are socialized, however, have been less researched. In other words, we have little knowledge about how socialization shapes children's emotion experience and 
emotion expression.

Thus the purpose of this study was to investigate the socialization of affect in Mandarin parent-child interaction. Following Ochs and Schieffelin (1989) and Clancy (1999), we took 'affect' to be a broader term than 'emotion'; affect includes not only emotion but also feelings, moods, disposition and attitudes associated with persons and/or situations. While affect can be conveyed verbally or nonverbally, this study focused on how Mandarin-speaking children and their parents display affect through linguistic means. While languages afford a variety of linguistic means for encoding feelings (Irvin 1982), the affect lexicon is a major source and has received the most attention. For the purpose of this study, we focused on the affect lexicon and analyzed how affect words were used in parent-child interaction in the socialization process.

\subsection{Language socialization}

The notion of language socialization involves sociological, anthropological, and psychological approaches; it concerns the study of social and linguistic competence within a social group. According to Schieffelin and Ochs (1986), socialization is the process by which children become competent members of their social group. The process begins at the first moment of social contact, and language plays an important role in this process. It has been shown that conversational activities involving small children are related to culture belief, values, and social order. Language thus can serve as a major source for children to learn information concerning the world views of their culture. As also suggested by Bernstein (1975) and Cook-Gumperz (1973), children acquire social knowledge as they acquire knowledge of language structure and use. The socializing function of input language was also pointed out by Gleason and Weintraub (1978). Gleason and Weintraub emphasized the role of input in instructing children in specific cultural and social information, including appropriate uses of language. Similarly, in Fischer's (1970: 107-108) framework, linguistic socialization concerns "the learning of the use of language in such a way as to maintain and appropriately and progressively change one's position as member of society".

It appears that the notion of language socialization concerns two major perspectives, namely socialization through the use of language and socialization to use language (Schieffelin \& Ochs 1986). In other words, we can investigate how language is used as a medium or tool in the socialization process; in addition, we can also investigate the acquisition of the appropriate uses of language as part of acquiring social competence. As the process of language acquisition and the process of socialization are integrated, the notion of language socialization can be expressed in the following two claims:

1. The process of acquiring language is deeply affected by the process of becoming a competent member of a society.

2. The process of becoming a competent member of society is realized to a large extent through language, by acquiring knowledge of its functions, social distribution, and interpretations in and across socially defined situations, i.e., through exchanges of language in particular social situations.

(Ochs \& Schieffelin 1984: 277).

As for the process of language socialization, it has been suggested that language socialization is an interactive process. That is, the child is not a passive recipient but rather an active contributor to the outcome of interactions (Ochs 1986; Ochs \& 
Scheiffelin 1983; Schieffelin \& Ochs 1986; Wentworth 1980). The interactional character of socialization is also consistent with the Vygotskian framework, which emphasizes the facilitative role of competent members. According to Vygotsky (1978), the gap between what a novice has already mastered (the actual level of development) and what he or she can achieve when provided with support (potential development) is called 'the zone of proximal development'. Thus, in the socialization process the child develops skills in the 'zone of proximal development' with the guidance and collaboration from adults (Cazden 1981; Rogoff \& Lave 1984; Vygotsky 1978; Wertsch 1985; Wertsch, Minick \& Arns 1984).

\subsection{Development and socialization of affect}

Previous studies of children's emotional development have shown that various emotions appear at different times over the first few years. At birth, babies show interest, distress, disgust and contentment. Other emotions such as anger, sadness, joy, surprise and fear emerge between 2;6 and 2;7 (Izard et al. 1995). It has been suggested that these so-called primary emotions are biologically programmed (Camras et al. 1992; Izard 1982, 1993). Later in the second year, infants begin to display such complex emotions as embarrassment, shame, guilt, envy, and pride. It has been suggested that these emotions depend, in part, on cognitive development (Lewis et al. 1989).

The ability to recognize and interpret others' emotional displays improves throughout childhood. For example, 2- to 3-year-olds understand that emotion is associated with the fulfillment of desires, and 4- to 5-year-olds are able to appreciate the more complex linkages among emotion and thoughts, beliefs, and expectations (Bartsch \& Wellman 1995; Flavell \& Miller 1998; Wellman 1990). Jenkins and Ball (2000) investigated whether children between 6 and 12 years old were able to differentiate between the emotions of anger, sadness, and fear in terms of the social regulatory aspects of emotion. In addition, they also attempted to understand how children's understanding of the social-regulatory aspects of emotion change with age. The results showed that children as young as 6 years recognize that that there are different consequences for social interaction when anger is expressed, than when fear and sadness are expressed. In addition, children also think that the social goals of someone expressing anger are different from the social goals of someone expressing sadness or fear. The differentiation between anger, sadness, and fear was greater in older than in younger children.

From a socialization perspective, it has been suggested that each society has a set of emotional display rules that specify the circumstances under which various emotions should or should not be expressed (Gross \& Ballif 1991; Harris 1989). It appears that the expression of emotion is culture- and language- specific. For example, one language may have a lexical item for an emotion but other languages may not have an equivalent label. Or, one language may have distinct lexical items for emotions that other languages do not differentiate lexically (Clancy 1999; Russel 1991; Wierzbicka 1992). For example, Polish does not have a word corresponding exactly to the English word disgust. An Australian aboriginal language, Gidjingali, does not lexically distinguish 'fear' from 'shame', subsuming feelings kindred to those identified by the English words fear and shame under one lexical item (Hiatt 1978; Wierzbicka 1992). In other words, lexicons of affect are not universal representations of biologically given feeling states. As a result, acquisition of an affect lexicon is itself a socialization process to culture-specific ways of organizing emotional experience. When children begin to use 
affect words to interact with adults, language becomes an important vehicle for the cultural shaping of emotional experience. In other words, children's acquisition and uses of affect terms may reflect the structure of children's emotional experiences (Clancy 1999; Lewis \& Michalson 1982; Wierzbicka 1992). For example, according to Doi (1981: 169) amae ${ }^{1}$ is "a peculiarly Japanese emotion". It represents "the true essence of Japanese psychology" and is "a key concept for understanding Japanese personality structure" (Doi 1981: 21). It is also a concept which provides "an important key to understanding the psychological differences between Japan and Western countries” (Doi 1974: 310).

Previous research on the linguistic expression of affect has been based mainly on cross-cultural longitudinal investigations of children learning to talk. Ochs (1986) investigated linguistic conventions associated with affect in Samoan and how young children acquire knowledge of these conventions during development. Linguistic expressions of affect in Samoan included particles, interjections, pronouns, articles, phonology, address/reference terms, and adjectives of affect. It was found that Samoan children used linguistic expressions of affect from the single-word stage; most of the grammatical forms for expressing positive and negative affect were acquired before the age of four. Thus, the study supported the idea that children can express affect through conventional linguistic means from a very early point in their development.

Ochs (1988) further demonstrated the role of language in the socialization of love, fear and shame in Western Samoa. Ochs reported that caregivers in Western Samoa may use affect arousal as a control strategy to stop a small child from doing something harmful, distasteful, or otherwise 'wrong'. The feelings most commonly elicited and socialized by the caregivers include love, fear, and shame. Samoan caregivers often try to evoke empathy or love in a small child, in particular when they want the child to behave in a certain way. For example, caregivers may use grammatical structures or lexical items that express love to create or evoke a feeling of love and to induce the child to act in ways that display this feeling, i.e., to act sympathetically or supportively. Caregivers may also use fear to stop children from carrying out a wrongdoing. They warn and threaten the children by using a construction that predicates that some further action will take place, as in the elliptical predication Sasa! ('(I'm going to) hit (you)!'). In addition, caregivers may elicit the feelings of embarrassment and shame in a child to deter the child from doing certain acts like lying, stealing, or selfishly holding back food or money from others.

In Schieffelin (1986), Kaluli adults' interactions with children were investigated. The study focused on how Kaluli adults verbally tease and shame children to achieve a variety of ends. Instead of physical intervention, Kaluli adults prefer verbal manipulation through teasing and shaming when trying to influence others, especially small children. For the Kaluli, teasing and shaming are a systematic part of interactions with children. They are used to teach children how to be part of Kaluli society, to include them rather than set them apart. By doing so, Kaluli adults also socialize their children to do the same. In addition, Schieffelin (1990) further demonstrated language socialization of appeal, reciprocity and gender-appropriate behaviors in Kaluli culture.

Lewis and Michalson (1982) raised five questions concerning the socialization of emotions: (1) how to express emotions; (2) when to express emotions; (3) how emotions are managed; (4) how emotions are labeled; and (5) how emotional states are interpreted. In focusing on the fourth question, Lewis and Michalson studied the

1 According to Doi (1974), there is no single word in English (or in other European languages) equivalent to amae. As Doi explains, it indicates 'helplessness and the desire to be loved' (Doi 1981: 22). 
labeling of emotions by mothers that occurs during English mother-infant interaction. The participants of the study consisted of 111 one-year-olds and their mothers. Each mother and the infant had a 15-minute free play in a playroom, followed by the mother's departure from the playroom for not more than 2 minutes. The mother and the infant then had a 5-minute reunion, in which attachment behaviors could be observed. The mothers' use of emotion terms during the reunion was analyzed. It appeared that mothers' use of specific emotion labels was influenced by the mothers' socioeconomic status, verbal performance, maternal behaviors, and infant behaviors. The study demonstrated that mothers use emotion labels prior to their children's acquisition of language. The authors suggested that mothers who produce emotion labels provide their child with a linguistic experience that may facilitate the child's acquisition of emotion terms and that mothers who use a greater number of and more differentiated emotion terms may have children whose emotion experiences are more differentiated.

The socialization of affect in Japanese culture has also been studied. Clancy (1999) investigated how affect was socialized through language in a study of three middle-class Japanese mothers and their two-year-old children. The results showed that the mothers and their two-year-olds shared extensive affect lexicons. Such lexical expressions often occurred in clusters when the focus of talk was associated with affect. The affect lexicon consisted primarily of adjectives and verbs that encode specific emotional states or general evaluations with affective connotations. In addition, formulas arigatoo ('thank you') and gomen ('sorry') also occurred frequently. Clancy's results were consistent with studies of English-speaking children in that English-speaking children also resort primarily to adjectives and verbs to express affect at this stage (Beeghly, Bretherton \& Mervis 1986; Brown \& Dunn 1991; Wellman, Harris, Banerjee \& Sinclair 1995). From the analysis, Clancy proposed a model of the socialization of affect through language. Japanese children experience the socializing potential of affect talk in three ways: modeling of the affect lexicon by caregivers, direct instruction in the use of certain words, and participation in negotiations in which caregivers react to children's use of affect words. Following Schieffelin and Ochs (1986) and Vygotsky (1978), Clancy suggested that affect talk provides a foundation for children's mental representations of their own and others' affect and serves as a crucial vehicle of the socialization of affect.

Instead of examining affect lexicon, Suzuki (1999) investigated language socialization of affect through morphology in Japanese mother-child conversation. Suzuki analyzed the use of the suffix $-\mathrm{CHAU}^{2}$ by a Japanese mother in her interaction with her two-year-old son. Verbs inflected with -CHAU, a suffix expressing completion of a situation, carry negative connotations involving damage or physical harm to an entity. Thus, the mother's use of -CHAU reflected her negative affect upon completion of certain events or actions. By analyzing its form, frequency, meanings, and the way it was used in interaction, Suzuki demonstrated that -CHAU was a powerful tool of socialization, with which the mother regulated her child's behavior and taught the child how to display affect. The results showed that $28 \%$ of the mother's uses of -CHAU occurred when she negatively described the child's way of handling his toys. For example, the mother attached -CHAU to the verb kowareru 'breaking (his toys)' to portray that breaking toys is undesirable (kowarechau kara '(It) will break-chau'). The mother also used -CHAU to teach the child how to eat or treat food (21\%), as in the example oneesan ni ageta no mata totchatta noo? 'Have (you) taken-chatta away (the

${ }^{2}$-CHAU has two inflected forms, written in lower case: its non-past variant -chau, which contrasts with the past variant -chatta. 
food you) gave to big sister again?'. The mother also used -CHAU to teach the child about negative bodily conditions (32\%), as in yotchan no onaka koofuu ni konna ni harechatta no ne 'Yotchan's stomach has swollen-chatta so much like this'. In addition, -CHAU was also used by the mother to teach the child general knowledge about the physical world (19\%), as in the example when the child was trying to put toy cars on a toy bunk bed muri ja nai yotchan / okkotchau mon 'Isn't it impossible, Yotchan / (The cars) will fall-chau'. The framework of language socialization sheds new light on the analysis of the acquisition of -CHAU.

As for the socialization of affect in Chinese culture, Fung (1999, 2006) investigated the role of affect in moral socialization among Taiwanese preschool children, focusing especially on the socialization of shame. Fung's studies consisted of intensive and systematic observations of family interaction in the home setting and in-depth interviews with caregivers. It was found that the socialization of shame was well underway by age two-and-a half. Most of the events of shame were occasioned by the child's precipitating transgression, occurred in a playful manner, and involved the child's active participation. The child's rudimentary sense of shame was manipulated in order to teach right from wrong and to motivate the child to amend his or her behavior. The child was expected to respond, process, and comprehend the implicit moral message. It was suggested that these events were vivid illustrations of the practice of opportunity education - that is, situating the lesson concretely in the child's immediate experience.

As seen above, the work in cultural, linguistic and psychological anthropology has contributed to the study of the linguistic expression of affect and its role in language socialization. As suggested by Lewis and Michalson (1982), the acquisition of affect terms may reflect the interface between language acquisition, cognitive capacity and emotional experience; in addition, it may also reflect the underlying properties of the social experience of that culture.

To gain a more complete picture of language socialization of affect in children, studies of different languages are needed, especially less-investigated languages. Little has been done to investigate this aspect of language acquisition in Mandarin Chinese. While Fung (1999, 2006) studied Mandarin-speaking children's data, the studies focused mainly on the socialization of shame. Much still needs to be done to systematically investigate the socialization of affect in children acquiring Mandarin Chinese. Thus, this study attempted to document affect words used in early Mandarin parent-child conversation from the perspective of language socialization. In addition, previous studies have shown that from around 20 months children use emotion-descriptive terms in daily interaction, and that there is a dramatic increase in the number of emotion terms in children's vocabulary between 24 and 36 months (Bretherton, Fritz, Zahn-Waxler, \& Ridgeway 1986; Dunn, Bretherton, \& Munn 1987; Ridgeway, Waters, \& Kuczaj 1985). This study thus attempted to examine children aged 2 to 3 since they are at a stage when their ability to speak about emotion burgeons. The analysis focused on the content, functions and conversational structures of the affect lexicons in the speech of the parents and the children.

\section{Methods}

\subsection{Participants and data}

The participants in this study were two Mandarin-speaking children, RON and LIN 
(pseudonyms), and their parents, who lived in the northern part of Taiwan. RON, a boy, was the only child in his family; LIN, a girl, had a younger sister. All of the parents were in their 30's; they had either a Ph.D. or a Master's degree, and were college professors/lecturers. The data used in this study consisted of eight hours of natural parent-child conversation video-taped at the children's homes, with four one-hour sessions with each child. RON's data were recorded at the ages of 2;1, 2;3, 2;9, and 3;0 and LIN's data were recorded at the ages of 2;2, 2;6, 2;10, and 3;1. In the data sessions, LIN interacted mainly with her mother while RON interacted mainly with his father. All of the data were collected in living rooms, and the two children and their parents were involved in similar activities during the data sessions, such as eating, reading books, and playing with toys. Other family members also occasionally participated in the interactions. The data were transcribed according to the CHAT conventions (MacWhinney 2000).

\subsection{Data analysis}

The analysis of the study included two parts, and was based mainly on Clancy (1999). The first part aimed to investigate the types of affect words used by the children and the parents, and the second part aimed to examine the data in terms of Clancy's model of the socialization of affect through language.

Every word with affective content or connotations in the speech of the parents and children were identified. The following five types of affect words were included:

(1) Type I: Predicates that encode a specific affective state and can take an experiencer as subject (e.g., gaoxing 'be glad').

(2) Type II: Predicates that describe a referent in terms of the affect it evokes (e.g., youqu 'interesting').

(3) Type III: Words having clear positive/negative valence (e.g., hao 'good'), including evaluative characterizations of people and their actions (e.g., yonggan 'brave') and descriptions of physical properties or sensory perceptions with affective connotations (e.g., haochi 'delicious').

(4) Type IV: Predicates referring to actions with affective motivations (e.g., $k u$ 'cry') and physical events or states with predictable positive or negative affective consequences (e.g., shoushang 'get hurt').

(5) Type V: Formulaic expressions of gratitude, apology, and regret (e.g., xiexie 'thank you').

Clancy's model of language socialization of affect includes the following three types of language socialization.

(1) Modeling: Children experience the socializing potential of language through observing their parents' use of affect words.

(2) Direct instruction: Children experience the socializing potential of language through being told by their parents to say or refrain from saying particular affect words.

(3) Negotiation: Children experience the socializing potential of language through participating in conversational sequences in which their parents react to their use of affect words. 
The data were coded for the types of affect words and for the ways of language socialization. The data were coded by two trained coders. Cohen's Kappa was used to determine the inter-rater reliability. The reliability for the coding of affect words was $\mathrm{K}=$ 0.93, and for the coding of socialization types was $\mathrm{K}=0.94$.

\section{Results}

Table 1 presents the total number of affect words in the parents' and the children's speech. As seen in Table 1, LIN's mother used about three times as many affect word tokens as LIN while RON's father used about two times as many as RON.

Table 1: Total number of affect words in the parent-child interaction

\begin{tabular}{lllll}
\hline Affect words & LIN & & RON & \\
\cline { 2 - 5 } & Child & Mother & Child & Father \\
\hline Total number & 187 & 578 & 207 & 409 \\
\hline
\end{tabular}

Further analysis was conducted to examine the types of affect words used in the children's and the parents' speech. A quantitative analysis was conducted to investigate the distributions of the five types of affect words; in addition, a qualitative analysis was conducted to examine how these words were used in the conversational interactions.

\subsection{Children's affect words}

The children's affect words were classified according to the five categories of affect words. Table 2 presents the number of tokens and the percentage of each type of affect words in the children's speech.

Table 2: The types of affect words in the children's speech

\begin{tabular}{lllll}
\hline Word types & LIN & & RON & \\
\cline { 2 - 5 } & Tokens & Percentage & Tokens & Percentage \\
\hline Type I & 129 & 69.0 & 143 & 69.1 \\
Type II & 24 & 12.8 & 11 & 5.3 \\
Type III & 14 & 7.5 & 40 & 19.3 \\
Type IV & 9 & 4.8 & 10 & 4.8 \\
Type V & 11 & 5.9 & 3 & 1.4 \\
\hline Total & 187 & 100.0 & 207 & 100.0 \\
\hline
\end{tabular}

As seen in Table 2, most of the children's affect words belonged to Type I (about $69 \%$ for both children). In other words, the children tended to use affect words to encode specific affective states, which was consistent with the findings of previous studies of Japanese-speaking children (Clancy, 1999) and of English-speaking children (Brown \& Dunn 1991; Wellman et al. 1995). In addition, it was found that in these cases the primary experiencers of the affective states were the children themselves. The encoded affective states included positive emotions such as 'xihuan' ('like'), 'kuaile' ('happy'), 'gaoxing' ('glad') and negative emotions such as 'haipa' ('afraid') and 'shengqi' ('angry'). 
Example 1 shows how RON used a positive Type I affect word 'xihuan' ('like') to encode his own affective state.

(1)

$\begin{array}{ll}\text { *FAT: } & \text { lai \# RON. } \\ & \text { come RON } \\ & \text { 'Come here, RON.' } \\ \text { *FAT: } & \text { zhe shi nide [= handing RON a doll]. } \\ & \text { this be yours } \\ \text { 'This is yours.' } & \\ \text { *FAT: } & \text { zhe shi Daniel [\%English], dui budui? } \\ & \text { this be Daniel right not right } \\ \text { *RON: } & \text { xihuan is Daniel, right?' } \\ & \text { like holding the doll]. } \\ \text { '(I) like you.' }\end{array}$

In this example, the father was handing a doll named Daniel to RON, and RON was able to express the affective state involved in the situation, with him himself as the experiencer ('(I ) like you').

Example 2, from LIN's data, shows how a negative state was encoded. In the example, LIN was saying that she was not afraid of entering a room alone.

(2)

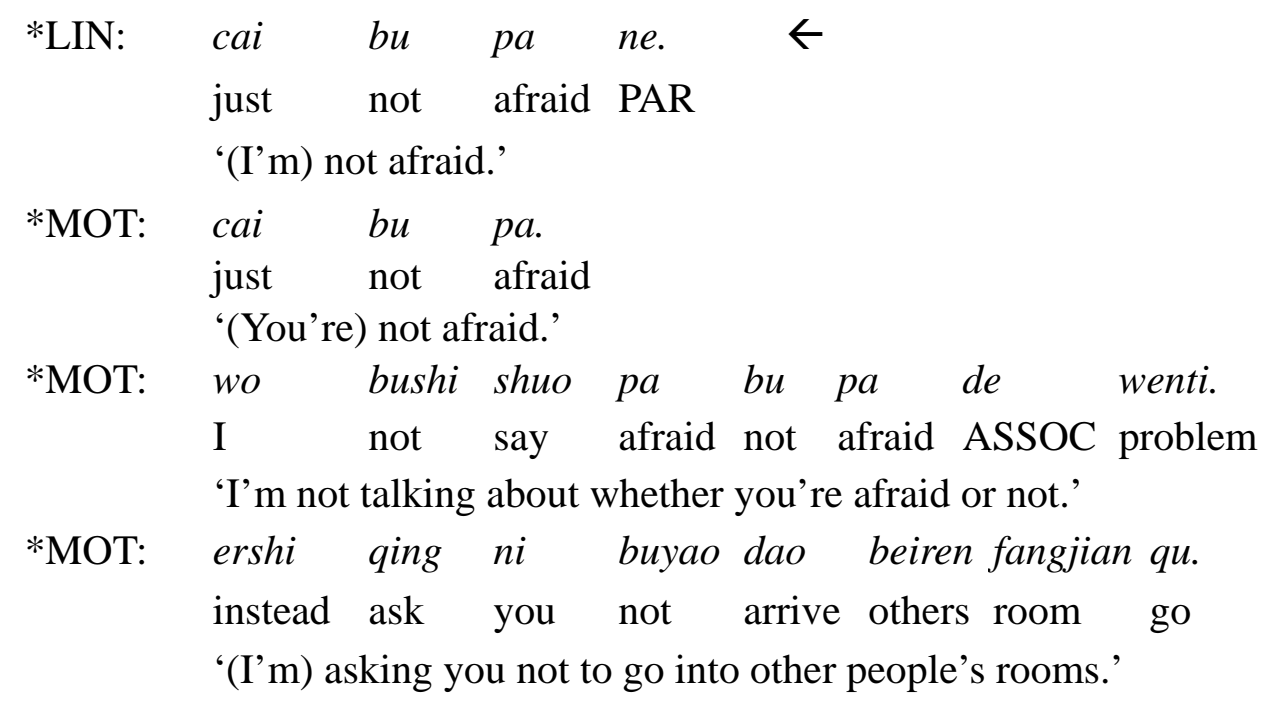

As seen in the example, LIN encoded the negative affective state 'pa' ('afraid') by negating the existence of the state. The experiencer was also the child herself.

In addition to encoding the positive and negative affective states, by far the most frequent Type 1 expressions, however, have to do with the children's wants and needs, 
that is, the use of the affect words 'yao' or 'xiangyao' ('to want').

(3)

$\begin{array}{ll}\text { *LIN: } & \text { wo yao he nainai. } \\ & \text { I } \text { want drink Milk } \\ & \text { 'I want to drink milk.' } \\ \text { *MOT: } & \text { yao he nainai a? } \\ & \text { want drink milk PAR } \\ \text { *MOT: } & \text { (You) want to drink milk?' } \\ & \text { wait a while PAR } \\ & \text { 'Just a second.' }\end{array}$

As seen in the above example, the children's use of 'yao' (want) often not only expressed their affective state but also functioned as a request. By expressing their 'wants', they expected their parents to carry out actions to fulfill their requests.

While the primary experiencers of the affective states were the children themselves, the children sometimes used Type I words to describe the affective states of the characters in the storybooks they were reading with their parents or in the pretend plays they were currently engaged in. In Example 4, LIN and her mother were reading a story about a lion and a rat. In this example, we observed that the child used several Type I affect words which denoted the affective states of the characters in the story.

(4)

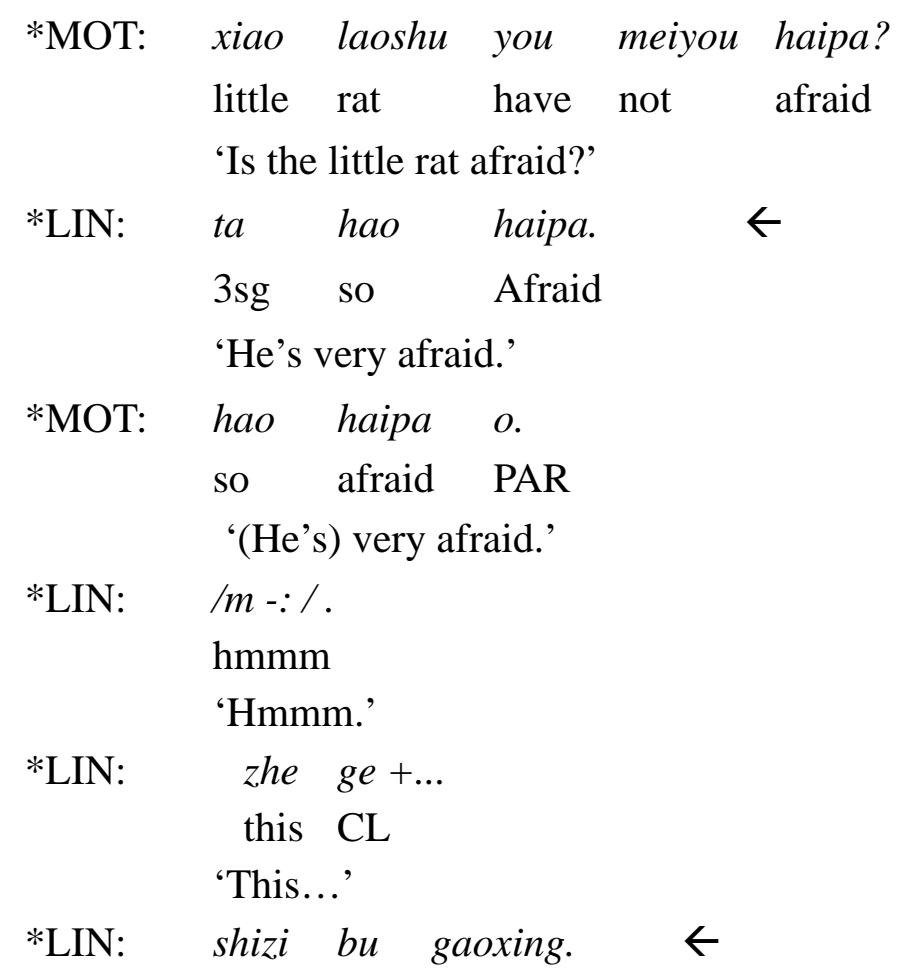


lion not happy

'The lion is not happy.'

*MOT: shizi bu gaoxing.

lion not happy

'The lion is not happy.'

*LIN: $\quad$ shizi shengqi. $\leftarrow$

lion angry

'The lion is angry.'

*MOT: $/ m /$ ta shengqi le o.

mm 3sg angry CRS PAR

'Yes, he’s angry.'

In the example, LIN used three affect words to encode specific affective states: 'haipa' ('afraid), 'bu gaoxing' ('not happy), and 'shengqi' ('angry'). The experiencers of these affects were the rat and the lion in the story.

As seen in the example above, stories appear to be rich contexts for affect talks. Similar results were also reported in research on English-speaking children (Bretherton and Beeghly 1982; Beeghly et at. 1986; Brown and Dunn 1991; Kuebli et al. 1995) and Japanese-speaking children (Clancy 1999). By attributing affect to the characters in a story, children demonstrated an understanding of the appropriate affect in a specific context. In addition, by describing the affective states of the characters in a story, children may expand their understanding of various affective states, including those which they may not have personally experienced.

\subsection{Parents' affect words}

In addition to the children's use of affect words, the parents' use of affect words was also examined. The parents' affect words were also classified according to the five affect word types. The results are presented in Table 3.

Table 3: The types of affect words in the parents' speech

\begin{tabular}{lllll}
\hline Word Types & LIN's mother & \multicolumn{3}{l}{ RON's father } \\
\cline { 2 - 5 } & Tokens & Percentage & Tokens & Percentage \\
\hline Type I & 226 & 39.1 & 107 & 26.2 \\
Type II & 104 & 18.0 & 43 & 10.5 \\
Type III & 158 & 27.3 & 189 & 46.2 \\
Type IV & 46 & 8.0 & 54 & 13.2 \\
Type V & 44 & 7.6 & 16 & 3.9 \\
\hline Total & 578 & 100.0 & 409 & 100.0 \\
\hline
\end{tabular}

As seen in the table, the distributions of the parents' affect words displayed different patterns from the distributions of the children's affect words. While both children tended to use Type I affect words, the parents' affect words belonged mostly to Type I and Type III.

However, it is interesting to note that while both of the parents used mostly Type I and Type III words, the two parents' affect words also presented different distributional patterns. As seen in the table, Lin's mother used Type I words more than Type III words 
(39.1\% vs. 27.3\%) but RON's father used Type III words more than Type I words (46.2\% vs. 26.2\%). In other words, LIN's mother tended to use Type I words to encode affective states while RON's father tended to use Type III words to express evaluative characterizations. Interestingly, in Table 2, we observed that RON also used more Type III words than LIN. It appeared that to some extent the children's use of affect words reflected the distribution patterns in the parental speech.

As the major affect word types used by the parents were Type I and Type III, the parents' uses of these two types of affect words were further examined. In the analysis of Type I words, it was found that while the children used Type I words mainly to encode the children's own affective states, only a few of the parents' Type I words were used to encode the parents' own affective states. Instead, the parents often used Type I words to query the children's affect, to attribute affect to the children, or to confirm, accept or reject the children's states of affect.

Example 5 shows how the parents used Type I words to reject the children's affective states. In Example 5, LIN and the mother were reading a story.

*MOT: eyu.

alligator

'Alligators'

*LIN: hao kepa o.

so scary PAR

'(They are) scary.'

*MOT: hao kepa.

so scary

'(They are) scary.'

*MOT: weishenme?

why

'Why?'

*MOT: $\quad$ bu pa [/] bu pa[/] bu pa. $\leftarrow$ not afraid not afraid not afraid

'Don't be afraid. Don't be afraid. Don't be afraid.'

*LIN: mama zai zheli.

mother DUR here

'Mommy is here.'

*MOT: dui.

right

'You're right.'

*MOT: mama zai zheli bu pa. $\leftarrow$

mother DUR here not afraid

'Mommy is here, (so) don't be afraid.'

As seen in the example, LIN said that alligators were scary and her mother comforted the child by saying that she did not need to be afraid since the mother was 
there accompanying her. Thus, the mother comforted the child by rejecting the child's affective state.

The parents also used Type I words to attribute affect to the children, as seen in Example 6. In the example, RON and the father were playing with magnets of various shapes and colors.

(6)

*FAT: $\quad$ zhe shenme [\% pointing at a yellow magnet on the table] ?

this what

'What's this?'

*FAT:

$\begin{array}{lllll}\text { RON } & \text { Zui } & \text { xihuan } & \text { de } & a ! \\ \text { RON } & \text { Most } & \text { like } & \text { NOM } & \text { PAR }\end{array}$

'This is what RON likes the most!'

*FAT: $\quad$ zhe ge shi shenme?

this CL be what

'What's this?'

As seen in the example, the father was pointing at a yellow magnet and saying that it was what RON liked the most, thus attributing the affective state to the child.

In addition to confirming/accepting/rejecting the children's states of affect and attributing affect to the children, the parents used Type I words most frequently in the cases of querying the children's affective states, as shown in Example 7.

(7)

$\begin{array}{ll}\text { *MOT: } & \text { ni } \quad \text { xi Bu xihuan youyong? } \\ & \text { you like Not like swim } \\ & \text { 'Do you like swimming?' } \\ & \text { *LINuan -: } \\ & \text { like } \\ & \text { 'I do.' }\end{array}$

From the above examples, we observed that the parents used Type I words to negotiate with the children the appropriate affective responses to a variety of stimuli. In other words, the parents socialized the children in the understanding of who, including the children themselves, would experience what affect in response to what stimuli through the use of Type I words.

As for the parents' use of Type III words, it was found that these affect words were mainly evaluative expressions which characterized the children or their actions, as seen in Examples 8 and 9.

*FAT: o -: fang de dui ya. 
oh put CSC right PAR

'Oh, you are arranging them in the right way.'

*FAT: hen bang a.

very excellent PAR

'(You're) excellent.'

In Example 8, RON and the father were playing with some magnets. As RON was arranging some magnets on a board, the father was giving a comment. It appeared that RON had arranged the magnets in a correct way. In Line 2, the father used an evaluative expression 'excellent' to praise the child.

(9)

$\begin{array}{ll}\text { *FAT: } & \text { zheyang weixian. } \\ & \text { this way dangerous } \\ & \text { 'This is dangerous.' } \\ \text { *FAT: } & \text { ni hui diedao. } \\ & \text { you will fall down } \\ & \text { 'You will fall down.' }\end{array}$

In Example 9, the child was sitting in a drivable toy car. The father saw that the child was trying to drive the toy car with one leg inside and one outside the car, and he warned the child about the danger of such behavior. The father's utterance in Line 1 showed how he used an evaluative expression 'dangerous' to characterize the child's behavior.

The parents also used Type III words in book-reading or pretend play contexts, in which the parents expressed affect through evaluating the story characters or the characters' actions, as shown in Example 10.

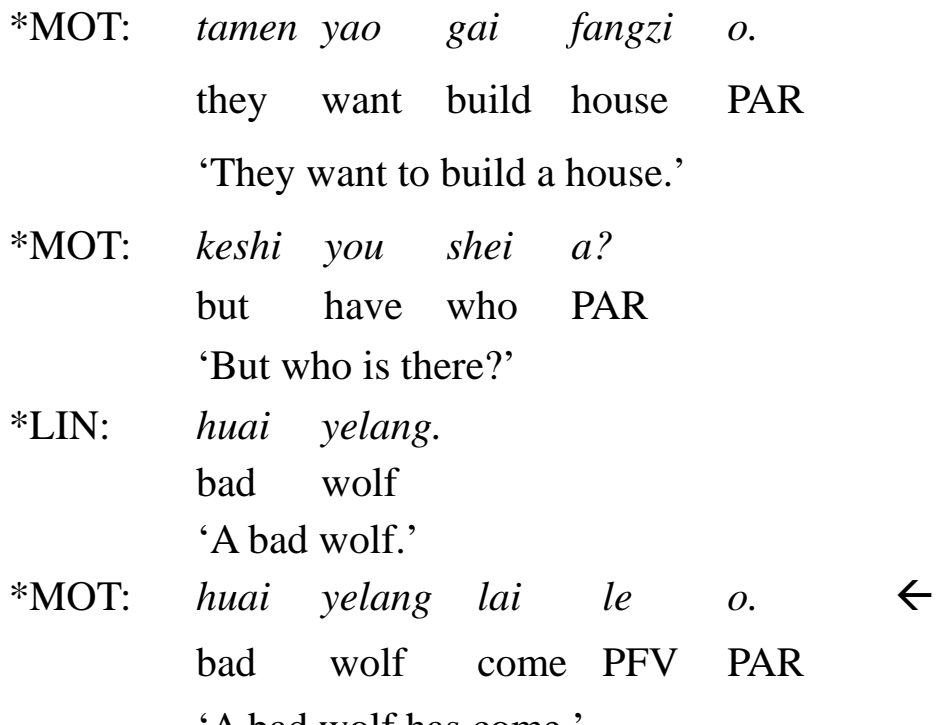

'A bad wolf has come.' 
In Example 10, LIN and the mother were reading a story book. As seen in Line 4, the mother used an evaluative expression 'bad' to characterize the wolf in the story.

From the above, we observed that by evaluating the children and their actions and by evaluating the characters in a story and their actions, the parents used these Type III evaluative expressions to directly or indirectly socialize the children's behaviors into culturally approved patterns.

\subsection{The socialization of affect through language}

A model of the socialization of affect through language has been proposed by Clancy (1999). It is suggested that children experience the socializing potential of language in three ways: (1) through modeling, i.e., observing their parents' use of affect words, (2) through direct instruction, i.e. being told by their parents to say or refrain from saying particular affect words, and (3) through negotiation, i.e., participating in conversational sequences in which their parents react to their use of affect words. It appears that this model can also be applied to our Mandarin parent-child data. In our data, the children also experienced the socialization of affect through modeling, direct instruction and negotiation.

\subsubsection{Modeling}

As suggested above, the children can observe their parents' use of affect words through the modeling provided by the parents. The data showed that in our Mandarin parent-child interaction, modeling also occurred when the parents expressed their own affect, as shown in Example 11. In Example 11, as the mother and the child were reading a story, the mother realized that she had misidentified some of the characters in the story and she said sorry to the child and made a correction.

$\begin{array}{lllll}\text { *MOT: } & \text { mami Gaocuo le \# duibuqi. } & & \\ & \text { mommy Mistake PFV Sorry } & & \\ \text { *MOT: } & \text { 'I made a mistake; I'm sorry.' } & & \\ & \text { zhe ge shi Xiaowanzi de } & \text { hao pengyou \# } \\ & \text { this } \text { CL be Xiaowanzi ASSOC good friend } \\ & \text { jiaozuo Xiaoyu. } & & \\ & \text { called Xiaoyu } & & \\ & \text { 'This is Xiaowanzi’s good friend, Xiaoyu.' } & \\ \text { *MOT: } & \text { zhe ge Shi Xiaowanzi de } & \text { jiejie. } \\ & \text { this CL Be Xiaowanzi ASSOC sister } \\ & \text { 'This is Xiaowanzi's sister.' } & \end{array}$

As seen in the example, by saying 'I'm sorry', the mother modeled the use of the affect word in an appropriate context, thus providing the child with information about the relationship between a particular stimulus, an experiencer, and a type of affect (Clancy 1999). 
The analysis showed that modeling also occurred when the parents attributed affect to third parties, as seen in Example 12. In this example, the child was stepping on a toy penguin.

$\begin{array}{ll}\text { *RON: } & \text { wo cai qi'e. } \\ & \text { I step on Penguin } \\ & \text { 'I'm stepping on the penguin.' } \\ \text { *FAT: } & n i \text { buyao Cai qi'e. } \\ & \text { you not step on Penguin } \\ \text { *FAT: } & \text { qi'e } \text { 'Don't step on the penguin.' } \\ & \text { penguin will Pain } \\ & \text { 'The penguin will feel pain.' }\end{array}$

As seen in the example, the father attributed a feeling of pain to the toy penguin, a third party. Through the modeling, the child not only observed the use of the affect word but also experienced socialization in behavioral appropriateness and empathy.

\subsubsection{Direct instruction}

In addition to modeling, the parents also used direct instruction for the socialization of affect. That is, the parents would directly ask the children to say or not to say particular affect words, as seen in Example 13. In this example, the grandaunt was visiting the family. As the grandaunt gave the child some chocolate, the father and the grandfather then taught the child what he should say in response.

$\begin{array}{ll}\text { *FAT: } & \text { You meiyou gen gupo } \\ & \text { Have not to grandaunt Thank } \\ \text { 'Did you say 'thank you' to Grandaunt?' } & \leftarrow \\ \text { *GRF: } & \text { Yao xiexie gupo. } \\ & \text { have to thank grandaunt } \\ \text { '(You) have to thank Grandaunt.' } \\ \text { *RON: Xiexie gupo. } \\ \text { Thank grandaunt } \\ \text { 'Thank you, Grandaunt.' }\end{array}$

In the example, we observed that both the father and the grandfather used direct instruction to socialize the child to use a formulaic expression of gratitude, namely 'thank you', to the grandaunt.

Example 14 demonstrates another case of direct instruction. In the example, the father and the child were playing with some toys and were involved in a pretend play. 
$\begin{array}{llll}\text { *FAT: } & \text { ni naqu gei agong chi. } \\ & \text { you take give grandpa } & \text { Eat } \\ & \text { 'You serve Grandpa this.' } & \end{array}$

*FAT: shuo agong \# zhe shi hen la hen la hen

say grandpa this be very spicy very spicy very

la de niupai. $\leftarrow$

spicy ASSOC Steak

'Say "Grandpa, this is a very, very, very spicy steak.",

*RON: zhe shi hen la hen la de

this be very spicy very spicy ASSOC

niupai [= giving a plate to Grandpa].

Steak

'This is a very, very spicy steak.'

*GFT: o\# xiexie xiexie.

oh thanks Thanks

'Oh, thank you, thank you.'

*GFT: aiyou \# hao la hao la hao la.

VOC so spicy so spicy so Spicy

'Wow, (it’s) very, very, very spicy.'

In this pretend play, we observed that the father taught the child what the child should say in the context. In Line 2, the father used the verb 'say' to elicit the child's repetition of his own utterance 'Grandpa, this is a very, very, very spicy steak'. We observed that in Line 2 the father in fact assumed the child's perspective and spoke from the perspective of the child.

\subsubsection{Negotiation}

In addition to modeling and direct instruction, the children also experienced socialization of affect through negotiation, which involved the children's use of affect words and the parents' reaction to such words. Such negotiations often followed certain common conversational sequences.

Example 15 reveals one of the common sequences: Question (P) - Answer (C) Acknowledgment $(\mathrm{P})$. That is, the sequence involved a question by the parent, an answer by the child, and an acknowledgment by the parent, as seen in Example 15. In Example 15, the mother and the child were telling a story. 
(15)

$\begin{array}{lll}\text { *MOT: } & \text { Xiao laoshu you meiyou haipa? } \\ & \text { Little rat have not } & \text { Afraid } \\ & \text { 'Was the little rat afraid?' } & \\ \text { *LIN: } & \text { ta hao haipa. } \\ & \text { 3sg So Afraid } \\ \text { *MOT: } & \text { hao haipa o. } \\ & \text { so afraid PAR } \\ & \text { '(He was) very afraid.' }\end{array}$

Another common sequence is shown in Example 16: Assertion (C) - Agreement (P). That is, the child's assertion was followed by the parent's agreement.

*LIN: Shizi shengqi.

lion Angry

'The lion is angry.'

*MOT: $/ m /$ ta Shengqi le o.

mm 3sg angry CRS Oh

'Yes, he’s angry.'

Example 17 shows another sequence: Assertion (C) - Counter-assertion (P). Such sequence involved an assertion by the child and a counter-assertion by the parent.

*RON: agong de toufa tai shao Le la. grandpa GEN hair too little CRS PAR

'Grandpa has too little hair.'

*FAT: buhui la \# agong de toufa bijiao chang. not PAR grandpa GEN hair rather Long

'That's not the case. Grandpa's hair is quite long.'

\subsubsection{Distributions of modeling, negotiation and direct instruction}

Further analysis was conducted to examine the distributions of modeling, negotiation and direct instruction across the sessions in the data. As seen in Figure 1, modeling occurred most frequently in LIN's data, and direct instruction occurred least frequently. The distribution patterns were similar across the four sessions. A Chi-square analysis 
was conducted to examine the distributions. While the Chi-square analysis showed a significant result $(\chi 2(6)=21.65, p<.01)$, the Post-Hoc multiple comparison test (Marascuilo \& McSweeney 1977) indicated that no significant difference was found in the comparison of any two of the four sessions (i.e., I vs. II; I vs. III , I vs. IV, II vs. III, II vs. IV, and III vs. IV) in any of the three types of socialization (i.e., modeling, negotiation, and direct instruction). In other words, the distribution patterns of the three types of socialization were similar across the four data sessions in LIN's data.

As for RON's data, Figure 2 also showed that modeling occurred most frequently, and direct instruction occurred least frequently. A Chi-square analysis was also conducted to examine the distributions, and the result did not reach significance ( $\chi 2$ (6) $=10.72, p>.05$ ); consequently, no significant difference was found in the comparison of any two of the four sessions in any of the three socialization types. Thus, RON's data also revealed similar distribution patterns across the four sessions.

Figure 1. Distribution of the types of socialization in LIN's data

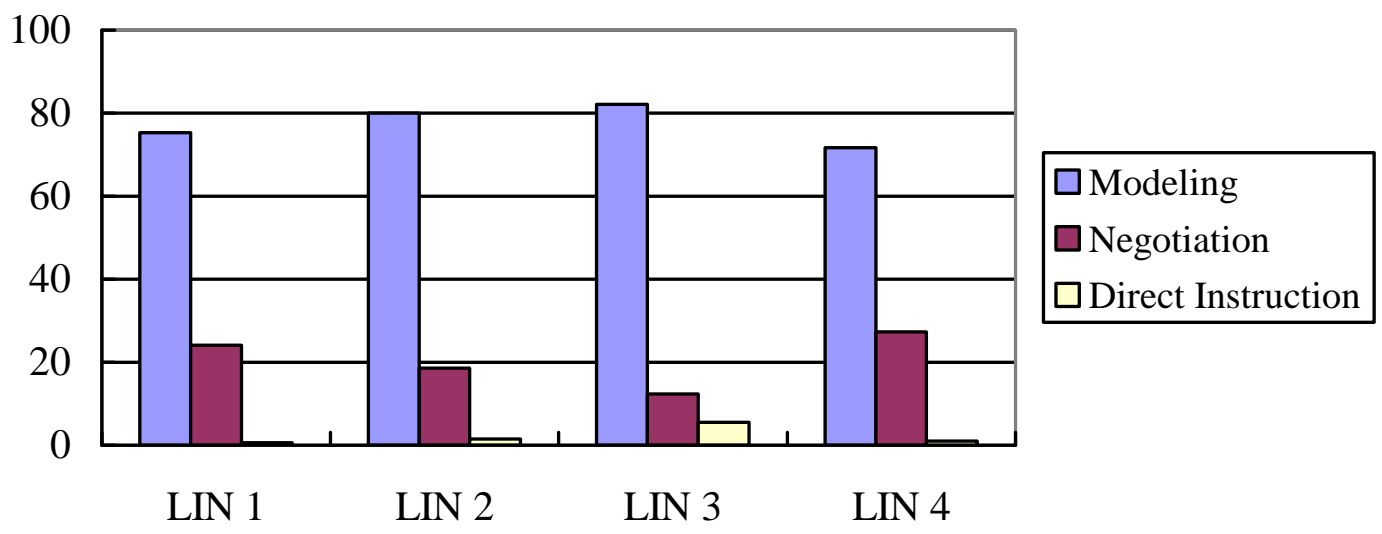

Figure 2. Distribution of the types of socialization in RON's data

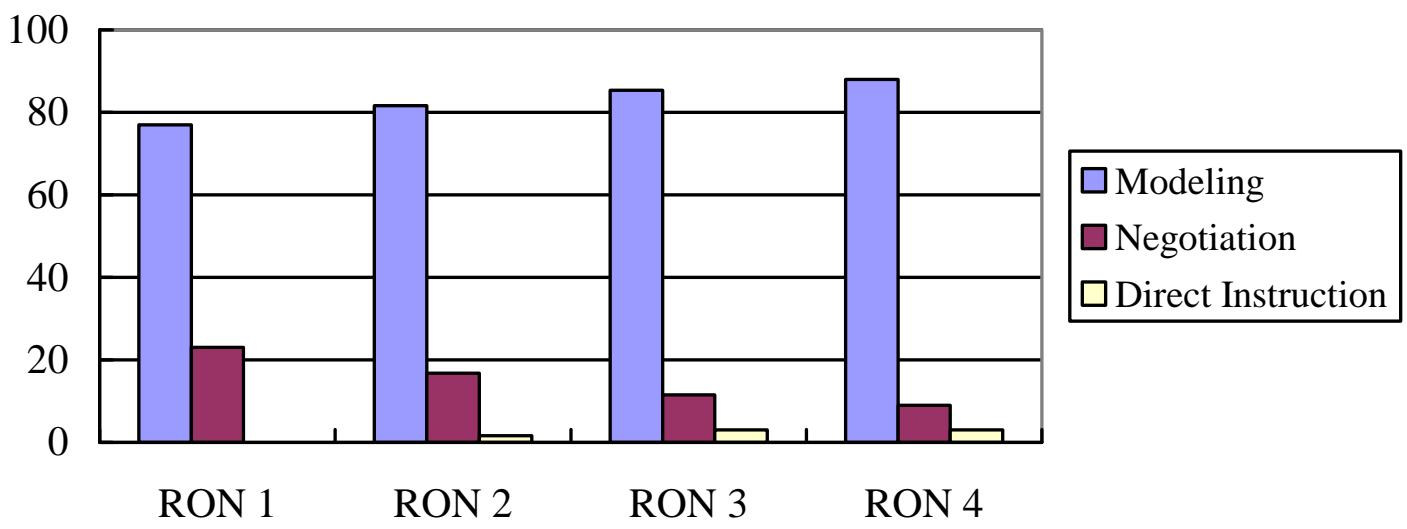




\section{Discussion and conclusion}

This study has investigated the use of affect words in Mandarin parent-child interaction. Some interesting findings have been obtained from our analyses. As seen above, both the parents and the children frequently used Type I words to encode specific affective states, often with the children as the experiencers. Through the use of Type I words, the parents socialized the children in the use of appropriate affective responses to a variety of stimuli. It appears that in Mandarin parent-child interaction, talking about the children's affective states, rather than the parents' or other third parties' affective states, is the focus in the socialization of affect. The result is consistent with those reported in the studies of English parent-child interaction (Brown \& Dunn 1991; Wellman et al., 1995) and Japanese parent-child interaction (Clancy 1999). The finding is related to the development of children's understanding of other people's affective states and the development of the theory of mind. The theory of mind involves the cognitive capacity of understanding that others have beliefs, desires and intentions that are different from one's own. With this capacity, one can comprehend the mind in relation to human behavior, and thus establish connections between mental states and related behavior. The finding of this study showed that the children tended to speak of their own states, suggesting that the children may not be able to readily understand and express other people's affective states. However, the results also demonstrated that the children's Type I words were not used exclusively to refer to self. A few Type I words in the data were used by the children to refer to others, which revealed that the children may have begun to use terms to denote the affective states of others.

The analysis also showed that stories or pretend plays can be good contexts for children to learn to talk about the affective states of third parties. In addition, stories and pretend plays can expand the variety of affect experiences which can be talked about by the children and the parents, thus expanding the children's affect understanding. For some affective states, especially negative ones, stories and pretend plays may provide a less threatening context for the conversational interaction (Brown \& Dunn 1991).

In addition to Type I words, it was found that the parents also used Type III words frequently. In fact, RON's father used more Type III words than Type I words. As observed above, the parents used Type III words mainly to evaluate the children or their actions; it appeared that these words were used by the parents to socialize and control the children's behavior. In other words, the parents' use of these Type III words is the most overt form of 'socialization through the use of language' (Schieffelin \& Ochs 1986). As mentioned in the Methods section, the parents of the two children were of similar age, and had similar educational backgrounds and occupations; in addition, the data of both of the parent-child dyads were collected in living rooms and involved similar activities. Thus, the fact that RON's father used more Type III words than LIN's mother was interesting. While the finding could be due to factors such as individual idiosyncrasies or differences in topic, a more likely explanation appeared to be the differences between maternal and paternal speech styles. Differences between fathers and mothers in the style and amount of talk to children are well-documented (e.g., Pine 1994; Snow 1995). Brachfeld-Child, Simpson and Izenson (1988) reported that fathers make greater efforts than mothers to control the situation and to direct their children's behavior. Thus, we may speculate that the different distributions of types of affect words in our parental speech data may reflect the different speech styles used by fathers and mothers to socialize children's affect and their behavior. That is, fathers may tend to 
discipline and evaluate their children more often than mothers do; thus, more Type III words can be found in fathers' speech. However, another possibility should be noted. Since LIN is a girl and RON is a boy, it is possible that parents tend to talk to their sons and daughters in different ways in affect talk. That is, socialization of affect experience may proceed differently for girls and boys (Kuebli et al. 1995; Leaper, Anderson \& Sanders 1998). Our results may indicate that parents usually try to control their sons' behavior more often than their daughters', and thus use more Type III words when talking to their sons. Therefore, we may speculate that the gender of parent and/or child influences the frequency of the parents' use of the different types of affect words in their interaction with their children. However, since we have only limited data, with one mother-daughter dyad and one father-son dyad, this study was not designed to yield conclusive results concerning the effect of parental and/or child gender differences. Therefore, further studies focusing on gender differences are needed in order to investigate gender-related patterns in parent-child affect talk.

Interestingly, while RON's father used more Type III words than LIN's mother, RON also used more Type III words than LIN. It appeared that the children's use of affect words reflected the distribution patterns of the input to some extent. In fact, we observed in the data that RON shared an extensive affect lexicon with his father, as did LIN with her mother. A number of studies have reported early gender differences in children's talk about emotions (Cervantes \& Callanan 1998; Dunn, Bretheron \& Munn 1987; Golombok \& Fivush 1994). Thus, whether our finding also reveals child gender differences in the use of affect expressions is worth further investigation. Furthermore, while the finding may reflect differences in the distribution of parental input and in child gender, it may also have to do with the conversational topics in the data. We observed in the data that affect expressions used by the parents and the children often occurred in clusters when affect-related topics were the focus of talk, a finding also reported in Clancy (1999). It appeared that when talking about affect-related topics, both the parents and the children tended to use the same types of affect words in the interaction.

As for the model of socialization, we have analyzed three types of socialization: modeling, direct instruction and negotiation. The results for both of the dyads revealed that modeling occurred most frequently while direct instruction occurred least frequently, and that the distribution patterns were similar across the four sessions. Clancy (1999) suggested that modeling is a major source of information about the relationships between particular stimuli, experiencers, and types of affect. Thus, the modeling of affect words is probably the primary basis for the acquisition of the affect lexicon by children. The claim was supported by our results, which showed that the parents relied heavily on modeling to socialize the children in acquiring affect lexicon. The results also revealed that the parents also relied on negotiation. In negotiation, the children experienced the socializing potential of language through participating in conversational sequences in which their parents reacted to their use of affect words (Saarni 1989). As seen in the analysis, negotiation also served as an important source of information about affect for the children. The strategy of direct instruction, on the other hand, occurred least frequently in the data. Direct instruction is regarded as a direct method of socialization (Saarni 1993), and is also the most overt form of the 'socialization to use language' (Schieffelin \& Ochs 1986). However, it appears that this direct method was less-preferred by the parents. This result is consistent with the findings reported in previous studies on parental input in relation to the development of preschoolers' communicative competence; these studies showed that most of the input from parents was indirect (Becker 1994; Bryant 1999). It was suggested that the use of 
direct input presents fewer cognitive challenges to children, and that it also provides less information about communicative conventions than indirect input (Becker 1988).

Given that so little research has been done on affect talk in Mandarin parent-child interaction, it is hoped that this study has shed some light on our understanding of the socialization process of affect expressions and affect lexicon in Mandarin child language. More longitudinal studies are needed in order to discover the developmental patterns of affect talk. Furthermore, as mentioned above, future studies should also investigate how parental and child genders may influence affect talk in parent-child interaction.

\section{References}

Bartsch, K., and H.M. Wellman (1995) Children talk about the mind. New York: Oxford University Press.

Becker, J.A. (1988) The success of parents' indirect techniques for teaching their preschoolers pragmatic skills. First Language 8: 173-181.

Becker, J.A. (1994) Pragmatic socialization: Parental input to preschoolers. Discourse Processes 17.1: $131-148$.

Beeghly, M., I. Bretherton, and C. Mervis (1986) Mothers' internal state language to toddlers. British Journal of Developmental Psychology 4: 247-261.

Bernstein, B. (1975) Class, codes and control. London: Routledge \& Kegan Paul.

Bretherton, I., J. Fritz , C. Zahn-Waxler, and D. Ridgeway (1986) Learning to talk about emotions: A functionalist perspective. Child Development 57: 529-548.

Bretherton, I., and M. Beeghly (1982) Talking about internal states: The acquisition of an explicit theory of mind. Developmental Psychology 18: 906-921.

Brown, J.R., and J. Dunn (1991) 'You can cry, mum': The social and developmental implications of talk about internal states. British Journal of Developmental Psychology 9: 237-256.

Bryant, J.B. (1999) Perspectives on pragmatic socialization. In A. Greenhill (ed.), Proceedings of the 23rd Annual Boston University Conference on Language Development, Vol.1. Somerville, MA: Cascadilla Press, pp. 132-137.

Brachfeld-Child, S., T. Simpson, and N. Izenson (1988) Mothers' and fathers' speech to infants in a teaching situation. Infant Mental Health Journal 9: 173-180.

Camras, L.A., H. Oster, J.J. Campos, K. Miyake, and D. Bradshaw (1992) Japanese and American infants' responses to arm restraint. Developmental Psychology 28: 578-583.

Cazden, C. (1981) Performance before competence: Assistance to child discourse in the zone of proximal development. Q. Newsl. Lav. Comp. Hum. Cognit. 1: 5-7.

Cervantes, C., and M. Callanan (1998) Labels and explanations in mother-child emotion talk: Age and gender differentiation. Developmental Psychology 34: 88-98.

Clancy, P.M. (1999) The socialization of affect in Japanese mother-child conversation. Journal of 
Pragmatics 31: 1397-1421.

Cook-Gumperz, J. (1973) Social Control and Socialization. London: Routledge \& Kegan Paul.

Doi, Takeo (1981) The Anatomy of Dependence: The Key Analysis of Japanese Behavior. English trans. John Bester (2nd ed.). Tokyo: Kodansha International.

Dunn, J.F., I. Bretheron, and P. Munn (1987) Conversations about feeling states between mothers and their young children. Developmental Psychology 14: 268-276.

Fischer, J.L. (1970) Linguistic socialization: Japan and the United States. In R. Hill \& R. Konig (eds.), Families in East and West. The Hague: Mouton, pp. 107-119.

Flavell, J.H., and P.H. Miller (1998) Social cognition. In W. Damon (Series ed.), D. Kuhn \& R.S. Siegler (eds.), Handbook of Child Psychology, Vol. 2: Cognition, Perception, and Language. New York: Wiley, pp. 851-898.

Fung, H. (1999) Becoming a moral child: The socialization of shame among young Chinese children. Ethos 27.2: 180-209.

Fung, H. (2006) Affect and early moral socialization: Some insights and contributions from indigenous psychological studies in Taiwan. In U. Kim, K.S. Yang, \&, K.K. Hwang (eds.), Indigenous and Cultural Psychology: Understanding People in Context. New York, NY: Springer, pp.175-196.

Gleason, J.B., and S.Weintraub (1978) Input language and the acquisition of communicative competence. In K.E. Nelson (ed.), Children's Language 1. New York: Gardner, pp. 171-222.

Golombok, S., and R. Fivush (1994) Gender Development. Cambridge: Cambridge University Press.

Gross, A.L., and B. Ballif (1991) Children's understanding of emotion from facial expressions and situations: A review. Developmental Review 1.1: 368-398.

Harris, P.L. (1989) Children and emotion: The development of psychological understanding. Oxford, England: Basil Blackwell.

Hiatt, L.R. (1978) Classification of the emotions. In L.R. Hiatt (ed.), Australian aboriginal concepts. Princeton, NJ: Humanities Press, pp. 182-187.

Hochschild, A.R. (1979) Emotion work, feeling rules, and social structure. American Journal of Sociology 85: 551-575.

Irvin, J.T. (1982) Language and affect: Some cross-cultural issues. In H. Burns (ed.), Contemporary Perceptions of Language: Inter-disciplinary Dimensions. Georgetown round table on language and linguistics. Washington, DC: Georgetown University Press, pp. 31-47.

Izard, C. E. (1977) Human emotions. New York: Plenum.

Izard, C. (1982) Measuring emotions in human development. In C. Izard (ed.), Measuring emotions in infants and children. New York: Cambridge University Press, pp. 3-18.

Izard, C.E. (1993) Four systems for emotion activation: Cognitive and noncognitive processes. Psychological Review 100.1: 68-90

Izard, C.E., C.A. Fantauzzo, J.M. Castle, O.M. Haynes, M.F. Rayias, and P.H. Putnam (1995) The ontogeny and significance of infants' facial expressions in the first 9 months of life. Developmental 
Psychology 31: 997-1013.

Jenkins, J.M., and S. Ball (2000) Distinguishing between negative emotions: Children's understanding of the social regulatory aspects of emotion. Cognition and Emotion 14: 261-282.

Kuebli, J., S. Butler, and R. Fivush (1995) Mother-child talk about past emotions: Relations of maternal language and child gender over time. Cognition and Emotion 9: 265-283.

Leaper, C., K.J. Anderson, and P. Sanders (1998) Moderators of gender effects on parents' talk to their children: A meta-analysis. Developmental Psychology 34: 3-27.

Lewis, M., and L. Michalson (1982) The socialization of emotion. In T. Field \& A. Fogel (eds.), Emotion and early interaction. Hillsdale, NJ: Erlbaum, pp. 189-212.

Lewis, M., M.W. Sullivan, C. Stanger, and M. Weiss (1989) Self development and self-conscious emotions. Child Development 60: 146-56.

MacWhinney, B. (2000) The CHILDES project: Tools for analyzing talk, 3rd ed. Mahwah, NJ: Lawrence Erlbaum.

Malatesta, C., and J.M. Haviland (1982) Learning display rules: The socialization of emotion expression in infancy. Child Development 53: 991-1003.

Marascuilo L.A., and M. McSweeney (1977) Nonparametric and distribution-free method for the social sciences. Monterey, CA: Brooks/Cole Publishing Company.

Ochs, E. (1986) Introduction. In B. Schieffelin \& E. Ochs (eds.), Language socialization across cultures. Cambridge: Cambridge University Press, pp. 1-13.

Ochs, E. (1988) Culture and language development: Language acquisition and socialization in a Samoan village. Cambridge: Cambridge University Press.

Ochs, E., and B.B. Schieffelin (1983) Acquiring conversational competence. London: Routledge \& Kegan Paul.

Ochs, E., and B.B. Schieffelin (1984) Language acquisition and socialization: Three developmental stories. In R. Schweder \& R. LeVine (eds.), Culture theory: Essays on mind, self and emotion. Cambridge: Cambridge University Press, pp. 276-320.

Ochs, E., and B.B. Schieffelin (1989) Language has a heart. Text 9: 7-25.

Ortony, A., G.L. Clore, and A. Collins (1988) The cognitive structure of emotions. Cambridge: Cambridge University Press.

Pine, J. M. (1994) The language of primary caregivers. In C. Gallaway \& B.J. Richards (eds.), Input and Interaction in Language Acquisition. New York: Cambridge University Press, pp. 15-37.

Ridgeway, D., E. Waters, and S.A. Kuczaj II (1985) The acquisition of emotion-descriptive language: Receptive and productive vocabulary norms for ages 18 months to 6 years. Developmental Psychology 21: 901-908.

Rogoff, B., and J. Lave (1984) Everyday cognition: Its development in social contexts. Cambridge: Harvard University Press.

Russell, J.A. (1991) Culture and the categorization of emotions. Psychological Bulletin 110: 426-450. 
Saarni, C. (1989) Children's understanding of strategic control of emotional expression in social transactions. In C. Saarni \& P. Harris (eds.), Children's Understanding of Emotion. Cambridge: Cambridge University Press, pp. 181-208.

Saarni, C. (1993) The socialization of emotion. In M. Lewis \& J. Haviland (eds.), Handbook of emotions. New York: Guilford Press, pp. 435-446.

Schieffelin, B.B. (1986) Teasing and shaming in Kaluli children's interactions. In B.B. Schieffelin \& E. Ochs (eds.), Language socialization across cultures. New York: Cambridge University Press.

Schieffelin, B. B. (1990) The give and take of everyday life: Language socialization of Kaluli children. Cambridge: Cambridge University Press.

Schieffelin, B.B., and E. Ochs (1986) Language socialization. Annual Review of Anthropology 15: 163-191.

Scherer, K.R. (1982) The assessment of vocal expression in infants and children. In C.E. Izard (ed.), Measuring emotions in infants and children. New York: Cambridge University Press.

Snow, C. (1995) Issues in the study of input: Finetuning, universality, individual and developmental differences, and necessary causes. In P. Flecher \& B. MacWhinney (eds.), Handbook of Child Language. Oxford: Blackwell, pp. 181-193.

Suzuki, R. (1999) Language socialization through morphology: The affective suffix -CHAU in Japanese. Journal of Pragmatics 31: 1423-1441.

Vygotsky, L.S. (1978) Mind in society. Cambridge: Harvard University Press.

Wellman, H.M. (1990) The Child's theory of mind. Cambridge, MA: Bradford.

Wellman, H.M., P.L. Harris, M. Banerjee, and A. Sinclair (1995) Early understanding of emotion: Evidence from natural language. Cognition 9: 117-149.

Wentworth, W.M. (1980) Context and Understanding: An Inquiry into Socialization Theory. New York: Elsevier.

Wertsch, J. (1985) Vygotsky and the social formation of mind. Cambridge: Harvard University Press.

Wertsch, J., N. Minick, and F.J. Arns (1984) The creation of context in joint problem solving. In B. Rogoff \& J. Lave (eds.), Everyday cognition: Its development in social contexts. Cambridge: Harvard University Press, pp. 151-171.

Wierzbicka, A. (1992) Semantics, culture, and cognition: Universal human concepts in culture-specific configurations. Oxford: Oxford University Press.

\section{Appendix}

Transcription symbols: 


$\begin{array}{ll}-: & \text { previous word lengthened } \\ +\ldots & \text { trailing off } \\ {[/]} & \text { retracing without correction } \\ {[\% \text { text }]} & \text { transcriber's comments } \\ {[=\text { text }]} & \text { explanation }\end{array}$

Abbreviations in the glosses:

$\begin{array}{ll}\text { ASSOC } & \text { associative } \\ \text { CL } & \text { classifier } \\ \text { CRS } & \text { currently relevant state } \\ \text { CSC } & \text { complex stative construction } \\ \text { DUR } & \text { durative aspect } \\ \text { GEN } & \text { genitive } \\ \text { PAR } & \text { particle } \\ \text { VOC } & \text { vocative } \\ \text { 3sg } & \text { third person singular pronoun }\end{array}$

CHIUNG-CHIH HUANG has a Ph.D. degree in Applied Linguistics from the University of California, Los Angeles. She is currently a faculty member in the Graduate Institute of Linguistics, National Chengchi University. Her research interests include first and second language acquisition, psycholinguistics, discourse pragmatics, and TESL.

Address: Graduate Institute of Linguistics, National Chengchi University, No. 64, Sec.2, Zhi-nan Rd., Wenshan District, Taipei 11605, Taiwan. E-mail: cchuang@nccu.edu.tw 